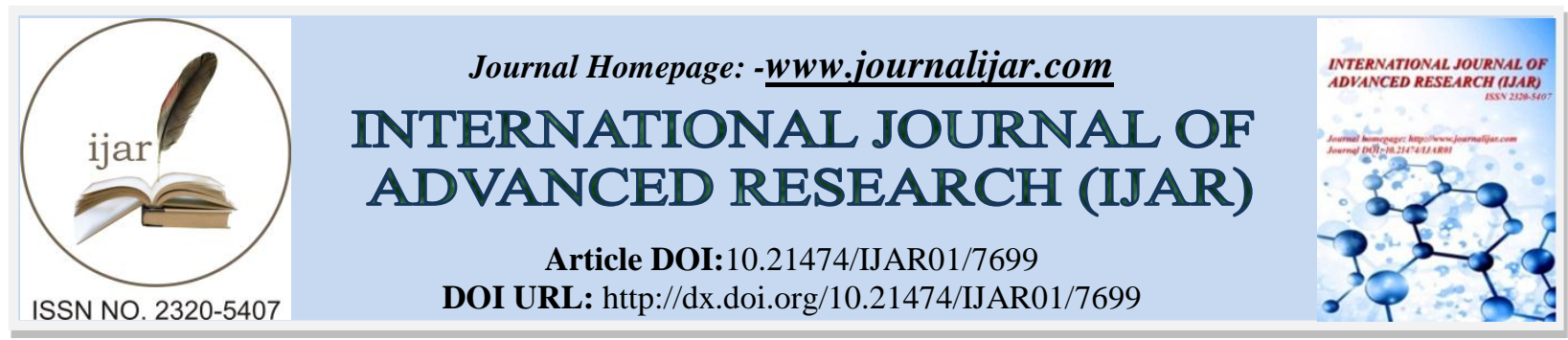

RESEARCH ARTICLE

\title{
16S RRNA CHARACTERIZATION OF CELLULASE PRODUCING BACILLUS CEREUS PREVALENT IN DECAYING AGRO WASTE.
}

Jaya Philip and Tanuja.

1. Department of Botany, BRABU, Muzaffarpur, Bihar, India.

2. Department of Botany, T.P.S College, Magadh University, Bihar, India.

\section{Manuscript Info}

Manuscript History

Received: 19 July 2018

Final Accepted: 25 August 2018

Published: September 2018

Keywords:-

Agro waste, cellulase; 16S rRNA characterization; Bacillus cereus, Bihar region.

\section{Abstract}

The present study was undertaken to isolate and screen an efficient cellulase producing bacteria from decaying agricultural waste. Bacterial cultures were isolated from agricultural wastes produced in the Bihar region. The preliminary isolation was done on nutrient agar media. The isolates obtained were screened for cellulase production by plating on $\mathrm{CMC}$ and Congo red agar media to observe the zone of cellulose hydrolysis. Out of 25 isolates 14 strains showed cellulase production on $\mathrm{CMC}$ and congo red agar. Further these isolates were used for crude enzyme production. The carboxy methyl cellulase (CMCase) activity was assayed using a method described by Miller, with some modifications. S18 bacterial isolate which showed maximum enzyme activity $(0.420 \mathrm{IU} / \mathrm{ml} / \mathrm{min})$ was further subjected to biochemical and molecular characterization. On the basis of molecular characterization, the isolates S18 was identified as Bacillus cereus. Therefore, the cellulase producing Bacillus cereus isolated and identified in this study from Bihar region have potential for further use and study, such as to isolate novel cellulases with unique characteristics. Also the enzymatic degradation of cellulose agrowaste produced in this region has been suggested as a possible alternative for the conversion of lignocelluloses substrate into fermentable sugars.

Copy Right, IJAR, 2018,. All rights reserved.

\section{Introduction: -}

Cellulose is the major constituent of plant biomass. Cellulose is the most abundant carbohydrate in nature and regarded as the most important renewable resource for bio-conservation. Cellulose is a crystalline polymer, an unusual feature among biopolymers. Microbial degradation of cellulosic waste and the downstream products resulting from it is accomplished by a concerted action of several enzymes, the most prominent of which are the cellulases, which are produced by a number of microbes and comprise different enzyme classification. Cellulases are bioactive compound which hydrolyze cellulose beta $(1,4) \mathrm{D}$ - glucan linkages and produce as primary products glucose, cellobiose and cello-oligosaccharides (Schulein, 1998)

Decaying agrowaste forms a significant part of domestic waste. Cellulolytic microorganisms degrade cellulose present in waste into other useful products. These play an important role in the biosphere by reducing complex polymer cellulose into various economically important products like monomeric sugars, microbial biomass proteins, compost, antibiotics etc, to everyday use for man. Biodegradation of organic contaminants occur due to production 
of extracellular enzymes by microorganisms. These contaminants can be considered as the substrate or microbial food source (Maier et al., 2000). Enormous amounts of agricultural, industrial and municipal cellulosic wastes have been accumulating or used inefficiently due to high cost of their utilization process (Oberoi et al., 2008).

Bacteria are well known agents of decomposition of organic matter in general and of cellulosic substrates in particular (Lynd et al., 2002). As bacteria can utilize wide range of cellulosic wastes, therefore, interest in the search for cellulase producing novel bacterial species is increasing. Such habitats which are rich in cellulosic substrates are the best sources in which cellulolytic organisms can be isolated. Bacteria has high growth rate as compared to fungi has good potential to be used in cellulose production. Some bacterial species viz., Cellulomonas species, Pseudomonas species, Bacillus species etc have cellulolytic property (Nakamura and Kappamura, 1982, Philip et al., 2016). A large number of microorganisms are capable of degrading cellulose, only a few of them produces significant quantities of cell-free bioactive compounds capable of completely hydrolyzing crystalline cellulose in vitro. Bacteria which have high growth rate as compared to fungi have good potential to be used in cellulase production (Sonia et al., 2013). Commercially produces enzymes are expensive, because they are produced from refined substrates and usually patented organisms. It is therefore crucial that cheaper substrates from local sources for enzyme production be investigated. The enzymatic degradation of cellulose waste has been recommended as a possible substitute for the conversion of lignocelluloses substrate into fermentable sugar. For understanding the mechanism of cellulose degradation by cellulase, it is necessary to isolate competitive strains. Therefore, the present investigation was designed to isolate and characterize the cellulase producing bacteria from decaying agro waste.

\section{Materials and Methods:- \\ Collection of samples:}

Decaying agricultural wastes from different regions of Patna were collected in sterilized polythene bags and were further processed within 24 hours of procurement.

\section{Isolation and screening of cellulose degrading bacteria:}

The samples were plated with sevenfold dilution on Nutrient agar plates by serial dilution method. The plates were incubated at $37^{\circ} \mathrm{C}$ for $24 \mathrm{hr}$. The colonies obtained were maintained on Nutrient agar. The isolates were screened for cellulase production by plating on CMC and Congo red agar media to observe the zone of cellulose hydrolysis. After incubation, the CMC agar plates with the isolates were flooded with Grams iodine solution to visualize the hydrolysis zone. The appearance of clear halos around the colonies confirms cellulase activity by the bacteria. More the ratio obtained in the either medium the more will be its efficacy for obtaining the enzyme cellulase in large amount (Maki et al., 2011). Also, the isolates that have the capability to produce cellulase cause the decolorization of congo red around the colony on the congo red media.

\section{Production of cellulase crude enzyme:}

Cellulase enzyme was produced using growth medium. The screened isolates were inoculated in a shaker incubator at $200 \mathrm{rpm}$ for $48 \mathrm{~h}$. Then the cell free extract was procured by centrifugation at $6000 \mathrm{rpm}$ for $15 \mathrm{mins}$ in a cooling centrifuge. The supernatant (crude enzyme) obtained was stored for further estimation.

\section{Estimation of cellulase enzyme activity:}

Estimation of Cellulase enzyme activity was assayed using Dinitrosalisic acid (DNS) reagent (Miller, 1959) by estimation of reducing sugars released from CMC. Crude enzyme was added to $0.5 \mathrm{ml}$ of $1 \% \mathrm{CMC}$ in $0.05 \mathrm{M}$ phosphate buffer and incubated at $50 \mathrm{C}$ for $30 \mathrm{~min}$. After incubation, the reaction was stopped by the addition of $1.5 \mathrm{ml}$ of DNS reagent and boiled at $100 \mathrm{C}$ in water bath for $10 \mathrm{~min}$. Sugars liberated were determined by measuring absorbance at $540 \mathrm{~nm}$ (Patagundi et al., 2014). Cellulase production was estimated by using glucose calibration curve (Shoham et al., 1999). One unit (U) of enzyme activity is expressed as the quantity of enzyme, which is required to release $1 \mathrm{~mol}$ of glucose per minute under standard assay conditions (Muhammad et al., 2012)

\section{Characterization of selected isolate on the basis of morphology and biochemical tests:}

The bacterial isolate showing maximum enzyme activity was selected for characterization on the basis of morphology and biochemical tests. The parameters investigated were colony morphology, Gram's reactions, motility, carbohydrate fermentation, catalase production, oxidase test, MR-VP reaction, casein hydrolysis, indole production, citrate utilization, cellobiose fermentation, starch hydrolysis and nitrate reductase activity. 
Molecular identification of the selected cellulolytic bacteria:

The selected bacterial isolate which showed maximum cellulase activity was further subjected to molecular identification by $16 \mathrm{~S}$ rRNA sequence analysis.

\section{Isolation of genomic DNA:}

Bacterial Genomic DNA was isolated using the InstaGeneTM Matrix Genomic DNA isolation kit. An isolated bacterial colony was picked and suspend in $1 \mathrm{ml}$ of sterile water in a microfuge tube. It was centrifuged for 1 minute at 10,000-12,000 rpm to remove the supernatant. Then $200 \mu \mathrm{l}$ of Insta Gene matrix was added to the pellet and incubate at $56{ }^{\circ} \mathrm{C}$ for 15 minutes. Further it was Vortex at high speed for 10 seconds and the tube was placed in a $100{ }^{\circ} \mathrm{C}$ in heat block or boiling water bath for 8 minutes. Finally, vortex the content at high speed for 10 seconds and Spin at 10,000 - 12,000 rpm for 2 minutes. In result, $20 \mu \mathrm{l}$ of the supernatant was used per $50 \mu \mathrm{l}$ PCR reaction.

\section{Identification of bacteria by sequencing of the 16S rRNA (PCR Protocol):}

Using below 16S rRNA Universal primers gene fragment was amplified using MJ Research Peltier Thermal Cycler (Tanuja and Philip, 2017)

\section{Primer Details:}

$1 \mu \mathrm{L}$ of template DNA was added in $20 \mu \mathrm{L}$ of PCR reaction solution. 27F/1492R primers was used for bacteria, and then PCR reaction was performed under following conditions: Initial Denaturation at $94^{\circ} \mathrm{C}$ for 2 min and then 35 amplification cycles at $94^{\circ} \mathrm{C}$ for $45 \mathrm{sec}, 55^{\circ} \mathrm{C}$ for $60 \mathrm{sec}$, and $72^{\circ} \mathrm{C}$ for $60 \mathrm{sec}$. Final Extension at $72^{\circ} \mathrm{C}$ for $10 \mathrm{~min}$. DNA fragments were amplified about $1,400 \mathrm{bp}$ in the case of bacteria. A positive control (E.coli genomic DNA) and a negative control in the PCR were included.

\section{Purification of PCR products:}

Unincorporated PCR primers and dNTPs were removed from PCR products by using Montage PCR Clean up kit (Millipore). The PCR product was sequenced using the 518F/800R primers. Sequencing reactions were performed using a ABI PRISM ${ }^{\circledR}$ BigDyeTM Terminator Cycle Sequencing Kits with AmpliTaq ${ }^{\circledR}$ DNA polymerase (FS enzyme) (Applied Biosystems).

$\begin{array}{ccc}\text { Primer Name } & \text { Sequence Details } & \text { Number of Base } \\ 27 \mathrm{~F} & \text { AGAGTTTGATCMTGGCTCAG } & 20 \\ 1492 \mathrm{R} & \text { TACGGYTACCTTGTTACGACTT } & 22\end{array}$

\section{Sequencing protocol:}

Single-pass sequencing was performed on each template using below 16s rRNA universal primers. The fluorescentlabelled fragments were purified from the unincorporated terminators with an ethanol precipitation protocol. The samples were resuspended in distilled water and subjected to electrophoresis in an ABI 3730 x 1 sequencer (Applied Biosystems).

$\begin{array}{ccc}\text { Sequencing Primer Details: } & & \\ \text { Primer Name } & \text { Sequence Details } & \text { Number of Base } \\ 785 \mathrm{~F} & \text { GGATTAGATACCCTGGTA } & 18 \\ 907 \mathrm{R} & \text { CCGTCAATTCMTTTRAGTTT } & 20\end{array}$

Sequence data was aligned and analyzed for Identifying the bacterial Sample.

Bioinformatics protocol and Construction of phylogenetic tree:

The 16S rRNA sequence was blast using NCBI blast similarity search tool. The phylogeny analysis of our sequence with the closely related sequence of blast results was performed followed by multiple sequence alignment. The program MUSCLE 3.7 was used for multiple alignments of sequences (Edgar 2004). The resulting aligned sequences were cured using the program Gblocks 0.91b. Finally, the program PhyML 3.0 aLRT was used for phylogeny analysis and HKY85 as Substitution model. PhyML was shown to be at least as accurate as other existing phylogeny programs using simulated data, while being one order of magnitude faster. The program Tree Dyn 198.3 was used for tree rendering. (Dereeper et al., 2008). 


\section{Results:-}

A Total of 25 bacterial cultures were isolated on Nutrient Agar media and labelled S1- S25. The isolates were screened for cellulase production by plating on CMC and Congo red agar media to observe the zone of cellulose hydrolysis. Among all 25 tested bacterial strains 14 strains showed cellulase production on CMC and congo red agar. Further these 14 isolates were used for crude enzyme production. The carboxy methyl cellulase (CMCase) activity was assayed using a method described by Miller, with some modifications. S18 bacterial isolate showed maximum enzyme activity $(0.585 \mathrm{IU} / \mathrm{ml} / \mathrm{min})$. Strain $\mathrm{S} 18$ was further subjected to gram staining (Fig 2) and biochemical characterization. The results of the physico-biochemical characteristic of S18 have been tabulated in table 1 .

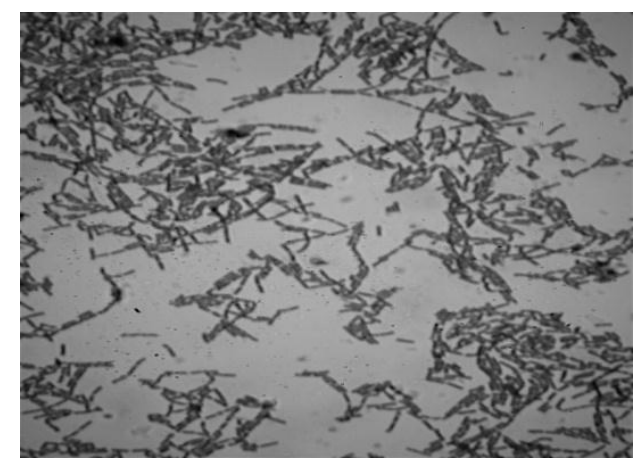

Fig.2: -Microscopic view of Bacillus cereus at 100X magnification of light microscope

Table 1: -Physio-biochemical characteristics of Bacillus cereus

\begin{tabular}{|c|c|}
\hline Gram staining & Gram + \\
\hline Cell shape & Rods \\
\hline Colony color & White \\
\hline Motility & + \\
\hline Spore & + \\
\hline Catalase & - \\
\hline Oxidase & + \\
\hline Methyl red & - \\
\hline Voges-Proskauer & + \\
\hline Indole & + \\
\hline Glucose fermentation & + \\
\hline Cellobiose fermentation & - \\
\hline fructose fermentation & + \\
\hline galactose fermentation & + \\
\hline Nitrate reductase & + \\
\hline Casein hydrolysis & \\
\hline Starch hydrolysis & + \\
\hline Gelatine hydrolysis & + \\
\hline Citrate utilization & \\
\hline
\end{tabular}

The highest cellulolytic enzyme producing strains S18 was further subjected to 16S rRNA sequencing. On the basis of molecular characterization, the isolate S18 was identified as Bacillus cereus. The Contig Summary and phylogenetic tree of Bacillus cereus obtained has been shown in Fig. 2 and Fig. 3 respectively.

$>$ Contig

GGTCTATACATGCAGTCGAGCGAATGGATTAAGAGCTTGCTCTTATGAAGTTAGCGGCGGACGGGTGA GTAACACGTGGGTAACCTGCCCATAAGACTGGGATAACTCCGGGAAACCGGGGCTAATACCGGATAA CATTTTGAACCGCATGGTTCGAAATTGAAAGGCGGCTTCGGCTGTCACTTATGGATGGACCCGCGTCG CATTAGCTAGTTGGTGAGGTAACGGCTCACCAAGGCAACGATGCGTAGCCGACCTGAGAGGGTGATC GGCCACACTGGGACTGAGACACGGCCCAGACTCCTACGGGAGGCAGCAGTAGGGAATCTTCCGCAAT GGACGAAAGTCTGACGGAGCAACGCCGCGTGAGTGATGAAGGCTTTCGGGTCGTAAAACTCTGTTGTT 
AGGGAAGAACAAGTGCTAGTTGAATAAGCTGGCACCTTGACGGTACCTAACCAGAAAGCCACGGCTA ACTACGTGCCAGCAGCCGCGGTAATACGTAGGTGGCAAGCGTTATCCGGAATTATTGGGCGTAAAGCG CGCGCAGGTGGTTTCTTAAGTCTGATGTGAAAGCCCACGGCTCAACCGTGGAGGGTCATTGGAAACTG GGAGACTTGAGTGCAGAAGAGGAAAGTGGAATTCCATGTGTAGCGGTGAAATGCGTAGAGATATGGA GGAACACCAGTGGCGAAAGGCGACTTTCTGGTCTGTAACTGACACTGAGGCGCGAAAGCGTGGGGAG CAAACAGGATTAGATACCCTGGTAGTCCACGCCGTAAACGATGAGTGCTAAGTGTTAGGAGGGTTTCC GCCCTTTAGTGCTGAAGTAACGCATAAGCACTCCGCCTGGGGGAGTACGGCCGCAAGGCTGATACTCA AGAATTGACGGGGGCCCGCACAGCGTGGAGCATGTGGTTATCGAGCACGCGAGGACTTACAGTCGTG ACATGCATCTGACACCCTAGAGATAGGCTGCGCTCGGAGCAGATGACAGTGTGCATGGATGTCGTCAG CTCTGTCCTGAGATGTAGGTTAAGTCGCAACGACGCAGCTTGACTTAGTGCATCATACTGGTCACCTGA GTACTGCGGTACGACGAGAGTGGATAGCTCGATCCATGCTGACTGGCTAACTGTTCCC ATGGACGTTCATTGA

Fig.3:- Contig Summary of Bacillus cereus

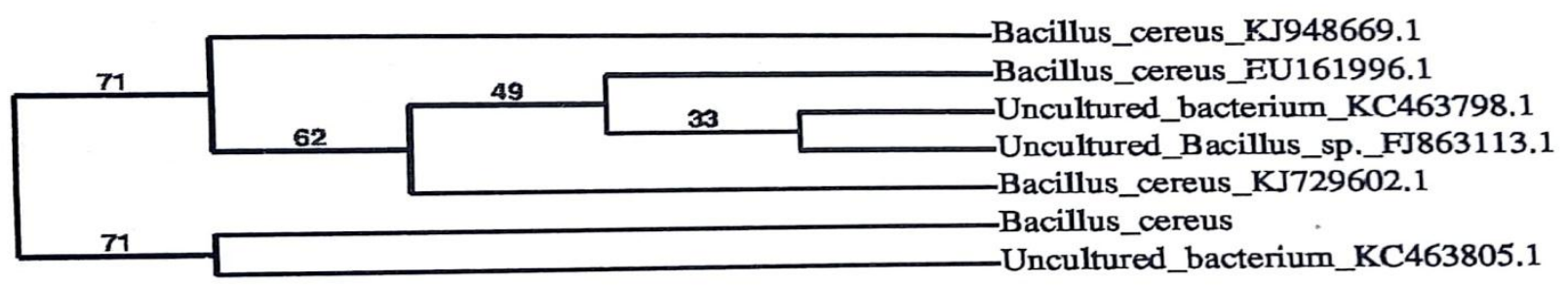

\section{Discussion:-}

Fig.4:- Phylogenetic tree of Bacillus cereus

Many efforts have been taken to generate microorganisms with high ability to produce cellulase that can degrade native cellulose (Aristidou and Penttila, 2000). Several microorganisms have been discovered which have capacity to convert cellulose into simple sugars (Perez et al., 2002). Among bacteria, Bacillus species have been reported to produce a number of extracellular enzyme including amylases, proteinases, and polysaccharide hydrolases (Mawadza et al., 2000). The result obtained in the present study is in accordance with outcomes of several other works reported earlier. Venkata et al., (2013) have reported that Bacillus cereus is one of the most promising bacteria to produce cellulase. Bacillus cereus has been found to produce the endoglucanase type cellulase (Afzal et al., 2012). Further, most of the isolated Bacillus strains were found to produce extracellular enzymes (Celenk et al., 2009). In a study conducted by Patagundi et al., 2014, that enzyme activity of cellulase producing Bacillus sp. characterized by $16 \mathrm{~S}$ rRNA sequencing ranged from $0.440 \mathrm{IU} / \mathrm{ml}$ to $0.334 \mathrm{IU} / \mathrm{ml}$ which is only slightly less than the activity shown by Bacillus cereus isolated in the present study. Similarly, Afzal et al., (2012) have reported 45.42 $\mathrm{U} / \mathrm{mg}$ cellulase production. In the work of Mukesh Kumar et al., (2012) cellulase activity of $66 \mathrm{U} / \mathrm{ml}$ in Bacillus cereus have been reported which was also identified by $16 \mathrm{~S}$ rDNA method. Thus, 16S rRNA sequencing used has proven useful for identification of strains and species (Gurtler \& Stanisich, 1996).

The results from this research show that introduction of cellulose degrading bacterial strains is a valuable tool of microbiology to support energy upturn from degraded ecosystems. Upon screening, finding isolate having cellulase activity is an indication of presence of cellulose decomposer in the decaying agrowaste that can break down large organic molecules into smaller molecules. This in turn will provide some medium to utilize renewable sources of energy with the help of micro organisms and processes they undergo during degradation of complex polymer to simpler sugars can be used in various industrial applications. Thus, the cellulase producing Bacillus cereus isolated and identified in this study have potential for further use and study, such to isolate novel cellulases having potential application.

Discovery of naturally occurring cellulose degrading bacteria from the environment is important to help prevail over expensive hurdles in the industrial processes. Optimization of different parameter of the production medium is required to get the maximum yield of the enzyme so that the cellulase producing isolates may be useful in producing efficient cellulase. 


\section{Acknowledgements:-}

The authors acknowledge the help received from the scholars whose articles are cited and included in references of this paper. The authors are thankful to all authors/ editors/ publishers of all those articles, papers, journals and books from where the literature for this article has been reviewed and discussed.

\section{References:-}

1. Afzal I., Shah A. A., Makhdum Z., Hameed A., Hasan F, 2012. Isolation and characterization of cellulase producing Bacillus cereus MRLB1 from soil. Minerva Biotecnologica September, 24(3):101-9

2. Aristidou A. and M. Penttila, 2000. Metabolic engineering applications to renewable resource utilization, Current Opinion in Biotechnology,11(2):87-98

3. Celenk Molva, Mert Sudagidan, Burcu Okuklu, 2009. Extracellular enzyme production and enterotoxigenic gene profiles of Bacillus cereus and Bacillus thuringiensis strains isolated from cheese in Turkey, Food Control 20 :829834

4. Dereeper A, Guignon V, Blanc G, Audic S, Buffet S, Chevenet F, Dufayard JF, Guindon S, Lefort V, Lescot M, Claverie JM, Gascuel O., 2008. Phylogeny.fr: robust phylogenetic analysis for the non-specialist. Nucleic Acids Res.1:3-6.

5. Edgar RC, 2004: MUSCLE: multiple sequence alignment with high accuracy and high throughput. Nucleic Acids Res, 32(5):1792-1797.

6. Gurtler, V. and Stanisich, V. A, 1996. New approaches to typing and identification of bacteria using the 16s-23s rDNA spacer region. Microbiology, 142, 3-16.

7. Lynd L. R., Weimer, P. J., van Zyl, W. H. and Pretorius, I. S., 2002. Microbial cellulose utilization: Fundamentals and biotechnology, Microbiology and Molecular Biology Reviews, 66(3), 506- 577

8. Maki M, Leung KT, Qin W., 2009. The prospects of cellulase-producing bacteria for the bioconversion of lignocellulosic biomass. Int J Biol Sci.; 5:500-516.

9. Maier RM, Peper IL, Gerba CP, 2000. Environment Microbiology, Academic Press.

10. Maki ML, Broere M ,Leung KT and Qin W., 2011 Characterization of some efficient cellulase producing bacteria isolated from paper mill sludges and organic fertilizers. Int J Biochem Mol Biol. 2(2): 146-154

11. Mawadza, C., Hatti-Kaul, R., Zvauya, R. and Mattiasson, B.,2000. Purification and characterization of cellulases produced by two Bacillus strains. J Biotechnol 83: 177187.

12. Miller G. L, 1959.Use of dinitrosalicylic acid reagent for determination of reducing sugar, Analytical Chemistry, vol. 31, no. 3, pp. $426-428$.

13. Muhammad Irfan, AsmaSafdar, Quratulain Syed, Muhammad Nadeem, 2012. Isolation and screening of cellulolytic bacteria from soil and optimization of cellulase production and activity. Turk J Biochem, 37 (3): 287- 293

14. Mukesh Kumar D. J, Poovai C. L, Puneeth Kumar, Sushma Saroja Y, Manimaran A. and Kalaichelvan P. T, 2012. Optimization of Bacillus cereus MRK1 cellulase production and its Biostoning activity, Der Pharmacia Lettre, 4 (3):881-888

15. Nakamura K, Kappamura K., 1982. Isolation and identification of crystalline cellulose hydrolyzing bacterium and its enzymatic properties. J Ferment Technol, 60 (4): 343-8.

16. Oberoi, H.S.; Yogita, C.; Sunil B.; Gurpreet, S. D., (2008). Production of cellulose through solid state fermentation using kinnow pulp as a major substrate. Food Bioprocess. Technol., 3(4),528-536.

17. Patagundi BI, Shivasharan CT, Kaliwal BB., 2014. Isolation and characterization of cellulase producing bacteria from soil, International Journal of Current Microbiology and Applied Sciences; 3(5):59-69.

18. Perez J, Munoz-Dorado J, de la Rubia T, Martinez J, 2002. Biodegradation and biological treatments of cellulose, hemicelluloses and lignin: an overview. Int Microbiol; 5 (2): 53 - 63.

19. Philip J, Tanuja T, Bedi S., 2016. Occurrence of Cellulose Degraders in Fruit and Vegetable Decaying Wastes. J Bioremediat Biodegrad 7: 373. doi: 10.4172/2155-6199.1000373

20. ShohamY, Lamed R, Bayer EA., 1999. The cellulosome concept as an efficient microbial strategy for the degradation of insoluble polysaccharides. Trends Microbiol 7(7):275 -281.

21. Schulein M,1998. Cellulases of Trichoderma reesei. In: Wodd WA, Abelson JN (eds) Methods in enzymology, vol 160. Academic, New York, pp 234-242

22. Sonia Sethi, Aparna Datta, B. Lal Gupta, and Saksham Gupta, 2013. Optimization of Cellulase Production from Bacteria Isolated from Soil. Hindawi Publishing Corporation, ISRN Biotechnology, ArticleID985685)

23. Tanuja and Philip J, 2017. Molecular Characterization of Cellulase Producing Microbacterium Barkeri Isolated from Agricultural Waste. Int. J. Adv. Res. 5(8), 1344-1349

24. Venkata Naga Raju E, Goli Divakar, T. Rajesh, Akram Ghazi, Asra Pourgharashi., 2013. Screening and isolation of cellulase producing Bacteria from dump yards of vegetable wastes. World journal of pharmacy and pharmaceutical res. 3(1): 428-435. 